\title{
Review
}

\section{The Impact of Deep Brain Stimulation on Sleep in Parkinson's Disease: An update}

\author{
José Rafael P. Zuzuárregui* and Jill L. Ostrem \\ Department of Neurology, University of California, San Francisco, CA, USA
}

Accepted 15 February 2020

\begin{abstract}
.
Background: Parkinson's disease (PD) can have a significant impact on sleep. Deep brain stimulation (DBS) is an effective treatment for motor features of PD, but less is understood about the impact DBS may have on sleep architecture and various sleep issues commonly seen in PD.

Objective: To review the impact of DBS on various sleep issues in PD.

Methods: We reviewed the literature regarding the impact of DBS on sleep patterns, nocturnal motor and non-motor symptoms, and sleep disorders in PD.

Results: Objective sleep measures on polysomnography (PSG), including sleep latency and wake after sleep onset improve after subthalamic nucleus (STN) and globus pallidus interna (GPi) DBS. Subjective sleep measures, nocturnal motor symptoms, and some non-motor symptoms (nocturia) also may improve. Current evidence suggests STN DBS has no impact on Rapid Eye Movement Behavior Disorder (RBD), while STN DBS may improve symptoms of Restless Legs Syndrome (RLS). There are no studies that have evaluated the impact of GPi DBS on RBD, while it is unclear if GPi has an effect on RLS in PD.

Conclusion: DBS therapy at either site appears to improve objective and subjective sleep parameters in patients with PD. Most likely, the improvement of motor and some non-motor nocturnal symptoms leads to an increase in total sleep time by up to an hour, as well as reduction of sleep fragmentation. DBS most likely has no impact on RBD, while there is evidence that STN DBS appears to help reduce RLS severity. Further studies are needed.
\end{abstract}

Keywords: Deep brain stimulation, Parkinson's disease, sleep, rapid eye movement behavior disorder, restless legs syndrome

\section{INTRODUCTION}

Parkinson's disease (PD) is a neurodegenerative disorder that is typically characterized by progressive rest tremor, bradykinesia, rigidity and gait instability. Non-motor features are often just as disabling as the motor features and can precede the clinical diagnosis of PD by many years [1]. Sleep disturbances are common in PD and are related to medication effect, as well as nocturnal motor and non-motor symptoms $[1,2]$.

\footnotetext{
*Correspondence to: José Rafael P. Zuzuárregui, MD, 1635 Divisadero Street, Suites 520-530, San Francisco, CA 94143, USA. Tel.: +1 415353 2311; Fax: +1 415353 9060; E-mail: rafael.zuzuarregui@ucsf.edu.
}

This includes but is not limited to tremor, painful dystonia, and nocturia leading to difficulty with sleep initiation and fragmentation of sleep $[1,2]$. Reductions in total sleep time, stage N3 sleep and quality of life are common (Fig. 1) [2-5]. Other sleep disorders in PD may include restless legs syndrome (RLS) and rapid eye movement behavior disorder (RBD) also negatively impact sleep and quality of life (Fig. 1) [2-5].

Deep brain stimulation (DBS) is an established treatment for PD motor symptoms, but less is understood about the effect of DBS on sleep. More literature is emerging that describes changes in sleep after DBS using polysomnography (PSG) testing and 


\begin{tabular}{|c|c|c|c|c|}
\hline Sleep architecture & & $\begin{array}{l}\text { Motor symptoms } \\
\text { Tremor } \\
+++\end{array}$ & $\begin{array}{l}\text { Nonmotor symptoms } \\
\begin{array}{l}\text { Nocturia } \\
+\end{array}\end{array}$ & Parasomnias \\
\hline $\begin{array}{c}\text { Reduced sleep } \\
\text { times } \\
++\end{array}$ & $\begin{array}{c}\text { Sleep } \\
\text { fragmentation } \\
+++\end{array}$ & \multirow[b]{2}{*}{$\begin{array}{c}\text { Dystonia } \\
+++\end{array}$} & \multirow[b]{2}{*}{$\begin{array}{l}\text { Hallucinations } \\
+/-\end{array}$} & $\begin{array}{c}\text { REM Behavior } \\
\text { Disorder } \\
+/-\end{array}$ \\
\hline & & & & \\
\hline $\begin{array}{c}\text { Reduced slow } \\
\text { wave sleep } \\
++\end{array}$ & $\begin{array}{l}\text { Poor sleep } \\
\text { efficiency } \\
+++\end{array}$ & $\underset{+++}{\text { Immobility in bed }}$ & $\begin{array}{c}\text { Restlessness } \\
++\end{array}$ & $\begin{array}{l}\text { Restless Legs } \\
\text { Syndrome } \\
+\end{array}$ \\
\hline
\end{tabular}

Fig. 1. Sleep disturbances in PD and the impact of DBS. This is representative of STN DBS given the relative paucity of data for GPi DBS. $+++=$ significant impact $+++=$ moderate impact $;+=$ mild impact $;+/=$ unknown or no impact.

various questionnaires. (Table 2). Here, we review the impact of DBS therapy on sleep architecture, nocturnal motor and non-motor PD symptoms, and sleep disorders in PD.

\section{METHODS}

We searched the literature using a combination of the following keywords: sleep, deep brain stimulation, Parkinson's disease, subthalamic nucleus, globus pallidus, restless legs syndrome, rapid eye movement behavior disorder. Databases searched included PubMED/Medline and The Cochrane Library. For the purposes of this review, studies evaluating objective and subjective sleep disturbances and/or disorders in patients with PD who underwent DBS were included. The evaluation of sleep disturbances needed to include PSG or validated questionnaires. Case studies, clinical trials and reviews were all included given the relatively small amount of literature on this subject. The methodological approach for this review differs from other analyses as it includes nearly the entire literature on this topic. We included 72 peer-reviewed studies published from 1986 to late 2019 in this review.

\section{RESULTS}

\section{Relationship of common PD DBS targets to sleep circuitry}

Wakefulness and sleep are promoted by a number of distinct neuronal circuits and neurotransmitters that interact in a complex fashion to regulate the sleep-wake cycle. Wakefulness is promoted by a number of neurotransmitters that are released by a diffuse system throughout the brainstem, hypothalamus and basal forebrain (Fig. 2). Important structures and neurotransmitters involved in wakefulness include the locus coeruleus (norepinephrine), parabrachial nucleus/precoeruleus area (glutamate), raphe nucleus (serotonin), ventral periaqueductal gray matter (vlPAG; dopamine), tuberomammillary nucleus (histamine) and the pedunculopontine tegmental nuclei (PPN; acetylcholine) [6]. Sleep is modulated by circuits in the brain and brainstem that promote both non-rapid eye movement (NREM) and rapid eye movement (REM) sleep [6]. NREM appears to be initiated by release of GABA by the ventrolateral preoptic area and median preoptic nuclei that inhibit the promotion of wakefulness system in the brainstem, thalamus and cerebral cortex [6]. The transition from NREM to REM occurs via a reciprocal switch in the brainstem. The lateral pontine tegmentum (LPT) and vlPAG inhibit the sublaterodorsal nucleus (SLD) and precoeruleus area (PA) during NREM. When REM is "turned on", the SLD and PA reciprocally inhibit the LPT and vlPAG, as well as activate the basal forebrain [6]. This switch also allows for suppression of motor activity during REM sleep that originates from the SLD and PA and ultimately inhibiting spinal cord motor neurons via the nucleus magnocellularis (Fig. 2) [6]. Control of NREM to REM sleep transition and the descending control of muscle tone may be disrupted by alpha- 

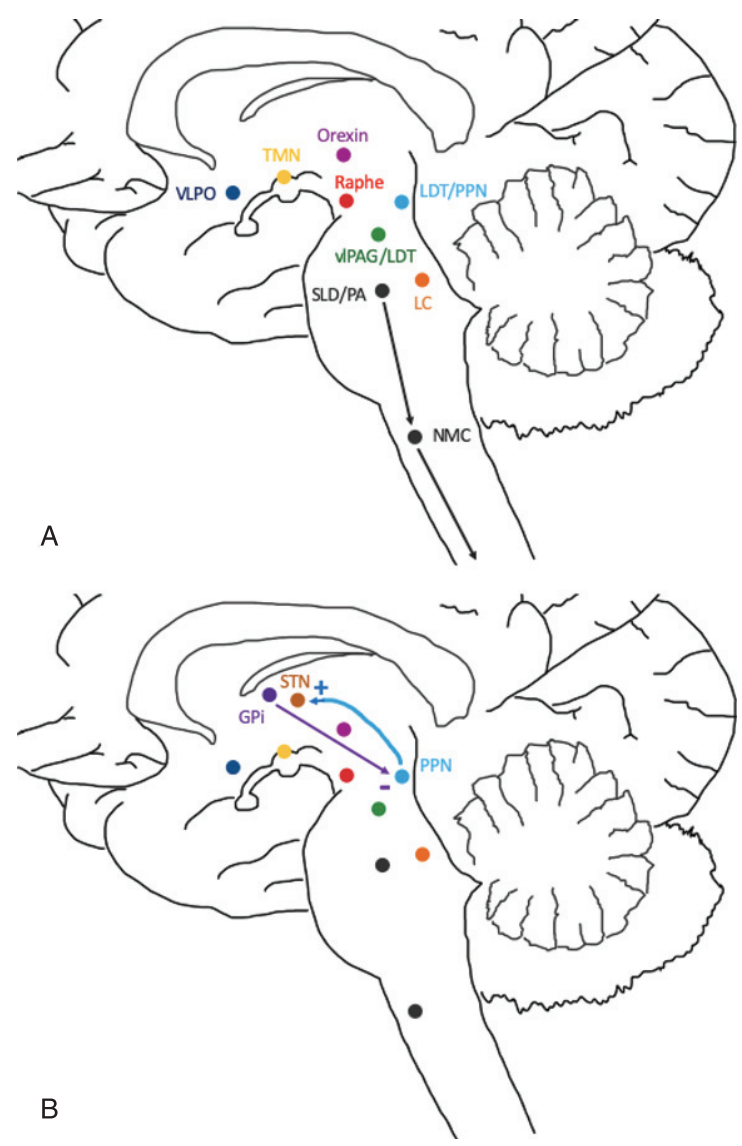

Fig. 2. Areas of sleep-wake control and proposed connection to DBS targets: STN and GPi. A) Wakefulness is promoted by the excitatory interaction between orexin, locus coeruleus (LC), precoeruleus area (PA), raphe nucleus, ventral periaqueductal gray matter (vlPAG), tuberomammillary nucleus (TMN) and pedunculopontine tegmental nuclei (PPN). Sleep is induced by the ventrolateral preoptic area (VLPO) which inhibits the above nuclei. During REM, the sublateral dorsal nucleus (SLD), PA and PPN inhibit the lateral pontine tegmentum (LPT) and vlPAG. The SLD and PA also inhibit spinal cord motor neurons via the nucleus magnocellularis (NMC) to promote REM atonia. B) The STN receives excitatory cholinergic projections from the PPN and may act as a relay for information regarding wakefulness and REM sleep. The GPi sends inhibitory GABA projections to the PPN, likely reducing wakefulness and suppressing REM sleep.

synuclein protein deposition in these nuclei in PD, which is suspected to lead to loss of REM atonia or RBD [7, 8].

The subthalamic nucleus (STN) is a common target for DBS in patients with PD. However, connectivity to the sleep-wake circuitry has not been well-established. Animal models demonstrate the PPN strongly modulates the neuronal activity of the STN via excitatory cholinergic projections, which may suggest a role of STN in processing information during REM sleep or wakefulness (Fig. 2B) [9-11]. A recent study evaluated the microlesion effect of STN DBS lead placement with fMRI and demonstrated a general increase in activity throughout the brainstem, though specific nuclei were not identified $[12,13]$. This suggests the STN heavily influences neuronal activity in the brainstem. Although a specific role for the subthalamic nucleus (STN) in sleep remains unclear, it appears to have significant connections with and influence on structures involved in the regulation of wakefulness and sleep.

The other common PD DBS target is the globus pallidus interna (GPi). This area receives dopaminergic projections from the midbrain and projects inhibitory GABA neurons to the PPN [11, 14-16]. In a study of sleep-wake behavior in rats, GPi lesioning led to a $45.5 \%$ increase in wakefulness [14]. Furthermore, GPi DBS in monkey primates restored inhibitory activity over the PPN, an important nucleus in the promotion of wakefulness and REM sleep [15]. Although its specific role still remains unclear, GPi appears to promote sleep via inhibition of the PPN when activated by dopamine neurons (Fig. 2B) [16].

\section{Impact of DBS on overall sleep in PD}

Though sleep disturbances have significant impact on quality of life in PD patients, careful study of the effect of DBS on sleep has only recently been evaluated in more detail. Early studies included no greater than twelve patients, with most demonstrating subjective improvements and benefit in total sleep time, sleep efficiency, continuous sleep time, and reduced wakefulness after sleep onset (WASO) up to two years post implantation (Table 2) [17-21]. Multiple studies have now evaluated the impact of both unilateral and bilateral STN DBS on objective and subjective sleep measures. The majority of these studies have used validated surveys to evaluate changes in sleep following STN DBS placement. One study evaluated the sleep quality of 53 patients prior to and following unilateral STN DBS placement with the Pittsburgh Sleep Quality Index (PSQI) [22]. This patient rated questionnaire measures sleep latency and overall sleep quality on a scale of 0-21 (Table 1) [23]. Higher scores represent worse sleep, while scores of 5 or more represent poor sleep quality. Significant improvement of the global PSQI was noted at six months in all patients $(9.3 \pm 0.6$ to $7.9 \pm 0.6$, $p=0.013$ ) [22]. When stratified by laterality, however, this improvement only remained significant in 
Table 1

Summary of questionnaires used to evaluate daytime sleepiness and various measures of subjective sleep quality and nocturnal symptoms in Parkinson's disease

\begin{tabular}{|c|c|c|}
\hline Questionnaire & Range & Sleep issue evaluated \\
\hline $\begin{array}{l}\text { Pittsburgh Sleep Quality Index } \\
\text { (PSQI) [23] }\end{array}$ & $0-21$ & $\begin{array}{l}\text { Seven-component questionnaire that assesses subjective measures of sleep } \\
\text { and daytime dysfunction. Higher scores represent worse sleep. Scores of } \\
5 \text { or more indicate poor sleep quality }\end{array}$ \\
\hline Epworth Sleepiness Scale (ESS) [25] & $0-24$ & $\begin{array}{l}\text { Eight-point questionnaire that assesses overall tendency to fall asleep } \\
\text { during the day. Higher scores represent worse sleep. Scores greater than } \\
10 \text { represent excessive daytime sleepiness. }\end{array}$ \\
\hline Insomnia Severity Index (ISI) [30] & $0-28$ & $\begin{array}{l}\text { Seven-point questionnaire that assesses severity of difficulty falling or } \\
\text { maintaining sleep. Higher scores represent worse sleep. Scores of } 10 \text { or } \\
\text { more identify insomnia. }\end{array}$ \\
\hline Unified Parkinson's Disease Rating & & Six section questionnaire that assesses the impact and severity of \\
\hline Scale (UPDRS) [32] & & $\begin{array}{l}\text { Parkinson's disease in multiple domains including mood, activities of } \\
\text { daily living, motor skills and complications of therapy. Part II and IV of } \\
\text { this questionnaire evaluate general problems turning in bed and sleep } \\
\text { disturbances, respectively. }\end{array}$ \\
\hline $\begin{array}{l}\text { Parkinson's Disease Sleepiness Scale } \\
\text { version } 2 \text { (PDSS-2) [36] }\end{array}$ & $0-60$ & $\begin{array}{l}\text { Fifteen-point questionnaire that assesses quality of sleep, as well as motor } \\
\text { and non-motor symptoms of Parkinson's disease that may disrupt sleep. } \\
\text { Higher scores represent worse nocturnal symptoms. }\end{array}$ \\
\hline $\begin{array}{l}\text { NMS Questionnaire (NMSQuest) } \\
\text { [45] }\end{array}$ & $0-30$ & $\begin{array}{l}\text { Thirty-point questionnaire which assesses non-motor symptoms of } \\
\text { Parkinson's disease, including sleep. Higher scores represent worse } \\
\text { nocturnal symptoms. }\end{array}$ \\
\hline $\begin{array}{l}\text { International Restless Legs } \\
\text { Syndrome Study Group Rating } \\
\text { Scale (IRLSS) [63] }\end{array}$ & $0-40$ & $\begin{array}{l}\text { Ten-point questionnaire that assesses the severity of restless legs. Higher } \\
\text { scores represent worse symptoms. Mild }=0-10, \text { moderate }=11-20 \text {, } \\
\text { severe }=21-30, \text { very severe }=31-40 .\end{array}$ \\
\hline
\end{tabular}

patients with right STN DBS therapy $(n=28)$ who had a higher baseline PSQI score than those with left STN DBS therapy $(n=25$; right STN baseline $10.3 \pm 3.8$ to $7.8 \pm 3.5$ at six months post-op; left STN baseline $8.3 \pm 3.7$ to $7.9 \pm 3.9$ at six months post-op) [22]. Bargiotas et al. reviewed 74 cases of patients with PD who underwent STN DBS and were surveyed with the Epworth Sleepiness Scale (ESS) [24]. The ESS has a total score ranging from 0-24 and scores greater than 10 representing excessive daytime sleepiness [25]. This study noted a significant improvement in the ESS one year following DBS, though the mean ESS scores at baseline and after intervention were not listed in the study [24].

The largest prospective study to date evaluating the impact of STN DBS on sleep with PSG included 50 patients with PD [26]. This study also included assessment with the ESS before and six months after DBS placement, as well as two-week actigraphy. Significant improvements were noted in the ESS score in this study after DBS $(9.4 \pm 4.6$ to $7.4 \pm 3.9)$. Sleep efficiency $(\% ; 73.6 \pm 16.0$ to $78.9 \pm 16.1)$, total sleep time (min; $275.4 \pm 68.1$ to $296.6 \pm 71.0$ ) and total slow wave sleep (min; $42.6 \pm 34.9$ to $53.8 \pm 43.3$ ) also significantly improved on PSG findings [26]. This corroborated previous smaller studies that STN
DBS placement improves both objective and subjective sleep measures.

Interestingly, one study evaluated different DBS stimulation frequencies and the impact on objective sleep measures [27]. Twenty PD patients with STN DBS were blindly randomized to three nights of PSG evaluation with one night at high frequency $(\geq 130 \mathrm{~Hz})$, one night at low frequency $(60 \mathrm{~Hz})$ and one night with DBS turned off. Settings were adjusted at $8 \mathrm{pm}$ on the night of each PSG, with at least three nights between PSGs. No significant differences were noted in objective sleep measures, including sleep efficiency $(\% ; 77.8 \pm 17.3$ vs. $71.6 \pm 22.5$ vs. $77.0 \pm 15.8)$ and total sleep time $(\mathrm{min} ; 357.9 \pm 98.7$ vs. $321.9 \pm 123.4$ vs. $349.1 \pm 73.6$ ). As patients were evaluated for only one night on each setting, the lack of change in sleep measures may be related to a delay in treatment effect. Future study of other stimulation settings may be of interest.

GPi DBS may also have an impact on overall sleep quality, though only one prospective study with five patients has evaluated this with the use of PSG [28, 29]. Increases in stage N2 and REM sleep were noted on PSG after DBS. There were also trends toward improvement in sleep latency ( $\mathrm{min} ; 60 \pm 76.2$ to $28.4 \pm 39.1$ ), sleep efficiency (\%; 
Table 2

Summary of studies evaluating the impact of DBS on sleep issues in PD

\begin{tabular}{|c|c|c|c|c|c|}
\hline Study & DBS site & Study size & Evaluation method & Follow-up & Effect of DBS \\
\hline Arnulf et al. [18] & STN & 10 & PSG & $3-6$ months & $\begin{array}{l}\text { Mean improvement in total sleep } \\
\text { time by } 47 \% \text {, reduction in } \\
\text { wakefulness after sleep onset by } 51 \\
\text { min }\end{array}$ \\
\hline Iranzo et al. [19] & STN & 11 & ESS, PSG, PSQI & 6 months & $\begin{array}{l}\text { No significant PSG changes, mean } \\
\text { PSQI improvement by } 63 \%\end{array}$ \\
\hline Monaca et al. [20] & STN & 10 & PSG, PSQI & 3 months & $\begin{array}{l}\text { Mean improvement in total sleep } \\
\text { time by } 28 \% \text {, sleep efficiency by } \\
40 \% \text {, PSQI by } 55 \%\end{array}$ \\
\hline Lyons et al. [21] & STN & 11 & ESS, UDPRS, time asleep & 24 months & $\begin{array}{l}\text { Slight increase in ESS, improvement } \\
\text { of total sleep time by } 1.3 \text { hours }\end{array}$ \\
\hline Bargiotas et al. [24] & STN & 74 & Actigraphy, ESS, PSG & 12 months & $\begin{array}{l}\text { Mean ESS improvement by } \sim 2, \text { PSG } \\
\text { not performed post-DBS }\end{array}$ \\
\hline Baumann-Vogel et al. [26] & STN & 50 & Actigraphy, ESS, PSG & 6 months & $\begin{array}{l}\text { Mean improvement in total sleep } \\
\text { time by } 1 \text { hour, reduction in ESS } \\
\text { by } 2.1 \text { and increase of sleep } \\
\text { efficiency by } 5.2 \%\end{array}$ \\
\hline Amara et al. [27] & STN & 57 & PSG, PSQI & 6 months & $\begin{array}{l}\text { Mean PSQI improvement by } 15 \% \\
\text { overall, however, only significant } \\
\text { in right STN group }\end{array}$ \\
\hline Tolleson et al. [29] & GPi & 5 & ESS, IRLSS, ISI, PDSS, PSG & 6 months & $\begin{array}{l}\text { Trend for improvement in all } \\
\text { measures, but no significant } \\
\text { changes }\end{array}$ \\
\hline Odekerken et al. [31] & STN/GPi & 118 & PDSS, UPDRS & 36 months & $\begin{array}{l}\text { Mean PDSS improvement of } 16 \% \\
\text { with STN, } 8 \% \text { with GPI }\end{array}$ \\
\hline Follett et al. [32] & STN/GPi & 299 & UPDRS, time asleep & 24 months & $\begin{array}{l}\text { Improvement of total sleep time by } \\
0.9 \text { hours in GPi and } 1 \text { hour in STN } \\
\text { group }\end{array}$ \\
\hline Weaver et al. [33] & STN/GPi & 121 & UPDRS, time asleep & 6 months & $\begin{array}{l}\text { Improvement of total sleep time by } \\
0.4 \text { hours in both groups }\end{array}$ \\
\hline Schuepbach et al. [34] & STN & 251 & UPDRS, time asleep & 24 months & $\begin{array}{l}\text { Improvement of total sleep time by } \\
0.5 \text { hours in DBS group }\end{array}$ \\
\hline Chahine et al. [37] & STN & 17 & ESS, IRLSS, PDSS & 6 months & $\begin{array}{l}\text { Mean PDSS improvement by } 33 \% \text {, } \\
\text { reduction of IRLSS by } 9.2\end{array}$ \\
\hline Nishida et al. [38] & STN & 10 & PDSS, PSG & $1-3$ months & $\begin{array}{l}\text { Mean PDSS improvement by } 18 \% \text {, } \\
\text { reduction in wakefulness after } \\
\text { sleep onset by } 72 \mathrm{~min} \text {, increase in } \\
\text { REM time by } 31 \mathrm{~min}(6 \%) \text { and } \\
\text { REM atonia by } 30 \mathrm{~min}\end{array}$ \\
\hline Breen et al. [39] & STN & 11 & PDSS & 6 months & Mean PDSS improvement by $18 \%$ \\
\hline Kurcova et al. [40] & STN & 24 & PDSS, NMS Quest & 4 months & Mean PDSS improvement by $9 \%$ \\
\hline Choi et al. [41] & STN & 46 & PDSS & 3 years & Mean PDSS improvement by $15 \%$ \\
\hline Deli et al. [42] & STN & 13 & PDSS-2 & 12 months & Mean PDSS-2 improvement by $58 \%$ \\
\hline Hjort et al. [43] & STN & 10 & PDSS-2 & 6 months & Mean PDSS improvement by $32 \%$ \\
\hline Hidding et al. [44] & $\mathrm{STN} / \mathrm{SNr}$ & 15 & PDSS-2 & & $\begin{array}{l}\text { Mean restlessness and immobility } \\
\text { scores lower in STN/SNr group }\end{array}$ \\
\hline Rukmini Mridula et al. [46] & STN & 56 & NMSQuest & 23 months & $\begin{array}{l}\text { Sleep disturbances }(25 \%) \text { and } \\
\text { nocturia }(21 \%) \text { less frequent in } \\
\text { DBS group }\end{array}$ \\
\hline Dafsari et al. [47] & STN & 60 & NMSQuest & 6 months & $\begin{array}{l}\text { Sleep (44\%) and urinary disturbances } \\
(27 \%) \text { less frequent in DBS group }\end{array}$ \\
\hline Kim et al. [54] & STN & 90 & RBD diagnostic criteria & 12 months & Onset of RBD in $18 \%$ \\
\hline Kedia et al. [64] & STN & 195 & RLS criteria & 4 months & $\begin{array}{l}\text { New onset RLS after DBS at rate of } \\
6 \%\end{array}$ \\
\hline Marques et al. [65] & STN & 31 & RLS criteria & 6 months & $\begin{array}{l}\text { New onset RLS after DBS at rate of } \\
19 \%\end{array}$ \\
\hline Driver-Dunckley et al. [66] & STN & 6 & IRLS rating scale & 3-24 months & Mean reduction of score by 20.8 \\
\hline Klepitskaya et al. [67] & STN & 22 & IRLS rating scale & 24 months & $\begin{array}{l}\text { Mean reduction of score by } 7.8,27 \% \\
\text { with complete resolution }\end{array}$ \\
\hline
\end{tabular}


$59.2 \pm 32.3$ to $72.6 \pm 14.6$ ) and periodic limb movement index (events per hour; $32 \pm 39.1$ to $6.8 \pm 9.8$ ) for the pooled data [29]. None of these changes were statistically significant, however. This study also included the ESS and Insomnia Severity Index (ISI). The ISI ranges from 0-28 and identifies insomnia with a score greater than 10 [30]. A high score on this survey represents worse sleep (Table 1). The ESS did not significantly change $(10.6 \pm 4.5$ vs. $11.0 \pm 4.7$; $p=0.85$ ), while the ISI trended towards improvement $(14.4 \pm 7.0$ vs. $9.0 \pm 2.6 ; p=0.07)$. The study size was likely too small to draw conclusions, though these positive trends are interesting.

Direct comparisons of DBS target on overall sleep effect are very limited. There has been only one study that evaluated the impact of DBS on sleep where patients $(n=90)$ were randomized to DBS target (STN or GPi) [31]. This study used the Parkinson's Disease Sleep Scale (PDSS) to identify the presence and severity of nocturnal symptoms that can occur in PD (Table 1). This tool has fifteen domains with an overall score that ranges from $0-150$. A lower score represents worse sleep, though clinically relevant values for this survey are not yet established. An improvement in mean overall PDSS scores of 12.1 was seen in the GPi group $(n=47)$ three years after DBS, while a mean overall improvement of 15.4 was seen in the STN group [31]. Analysis of each individual domain (tremor, akinesia, nocturia, etc.) was not performed, however, limiting assessment of these results.

\section{Impact of DBS on nocturnal motor and non-motor symptoms in $P D$}

Several randomized clinical trials have shown STN or GPi DBS is superior to best medical therapy for motor complications in PD [32-34]. These studies largely focused on evaluating changes in motor symptoms based on the United Parkinson's Disease Rating Scale Part III (UPDRS-III), while the patient is awake. A subjective evaluation of time spent asleep was measured by patient motor diaries in each trial. Total sleep time increased by nearly an hour in the three trials (range 0.4-0.9 hours) and trended towards significance, though recall bias may limit this result [32-34]. Nocturnal symptoms of PD were not specifically assessed in these studies, however, all studies evaluated UPDRS Part II and IV, which include an assessment of the patient's ability to turn in bed and adjust clothes, as well as any sleep disturbance. While individual assessments of these specific questions were not performed, a trend for improvement in overall scores for UPDRS part II and IV was found in each of the DBS groups in each trial [32-34].

Development and utilization of newer sleep scales including two versions of the Parkinson's Disease Sleep Scale (PDSS and PDSS-2) has helped to tease out specific improvement of nocturnal symptoms that may occur in PD (Table 1) [35, 36]. These 15-point questionnaires focus on subjective sleep measures, as well as nocturnal motor and non-motor features of PD, to provide an overall score for the impact of these features on sleep. Individual questions include motor features of tremor, immobility in bed and dystonia, as well as non-motor features such as nocturia, hallucinations and paresthesias. Clinically relevant thresholds have not yet been developed for these surveys.

\section{Parkinson's Disease Sleep Scale and Parkinson's Disease Sleep Scale-2 outcomes}

A number of studies have used the PDSS to evaluate changes in sleep quality following STN DBS for PD. This survey is scored from $0-150$ with a lower score indicating worse nocturnal symptoms [35]. One early study $(n=17)$ demonstrated a statistically significant improvement in overall PDSS scores following DBS at six months (94.2 to 122.9; $p<0.001$ ) [37]. Individual questions regarding motor and non-motor symptoms were not assessed specifically by this study. A similar study of ten patients also found that overall PDSS scores significantly improved at a mean follow-up of 68.8 days (96.0 \pm 18.4 to $115.3 \pm 16.5 ; p=0.01)$ [38]. There was no significant improvement in individual motor and non-motor questions, but a trend for improvement in the motor subset of questions was seen. [38]. Breen et al. evaluated 11 patients and found a trend for improvement in nocturnal restlessness (6.06 to $7.49 ; p=0.206$ ) and nocturia (5.69 to 6.91.4; $p=0.13$ ) at six months follow-up compared to baseline values, though none of these were statistically significant [39]. A similar study of 24 patients showed that overall PDSS scores significantly improved four months after DBS $(111.2 \pm 21.3$ to $121.7 \pm 23.4$; $p<0.05)$ [40]. The largest study with longest followup to date evaluated 46 patients up to three years after DBS, demonstrating significant and sustained improvement in overall PDSS scores compared to baseline $(79.0 \pm 30.0$ to $93.3 \pm 28.0 ; p<0.006)$ [41]. The nocturnal motor symptoms subset improved from $23.0 \pm 9.5$ to $29.2 \pm 8.9(p<0.001)$, while no 
other subsets demonstrated significant improvement [41].

Only one study has used the PDSS to evaluate sleep changes following GPi DBS [29]. Five patients were evaluated with the PDSS six months after DBS, showing an overall improvement from $90.2 \pm 20.4$ to $106.4 \pm 17.4$. Individual subsets were not analyzed and overall change was not statistically significant.

The PDSS-2 was revised to include more specific questions regarding restlessness, tremor, cramping and other motor symptoms [36]. The range was also changed to $0-60$, where a higher score indicates worse nocturnal symptoms. One study evaluated 25 PD patients with bilateral STN DBS one year after implantation [42]. Although a statistically significant improvement was seen in the total PDSS-2 score ( $24.8 \pm 9.9$ to $14.2 \pm 11.4 ; p<0.01)$, only a subset of questions showed significant improvement (tremor, akinesia, restlessness, cramps; $p<0.05$ ). Improvements in non-motor symptoms including nocturia and daytime fatigue were not significant [42]. Similar results were found in an earlier study of ten patients at three months post-implantation, where non-motor symptoms did not appear to improve significantly [43]. A recent double-blind, cross-over study used the PDSS-2 to evaluate 15 patients with STN stimulation alone versus simultaneous STN and substantia nigra pars reticulata stimulation (SNr). The overall PDSS2 scores were not significantly different between the STN and STN-SNr groups after stimulation. The STN-SNr significantly improved restlessness at night $(1.0 \pm 1.8 ; p=0.039)$ compared to STN alone $(1.9 \pm 2.7)$, as well as akinesia $(0.6 \pm 0.8$ vs. $1.5 \pm 1.4 ; p=0.041)$ highlighting the possible impact $\mathrm{SNr}$ stimulation may have on sleep in PD [44].

\section{NMS Questionnaire outcomes}

A handful of studies have specifically evaluated the frequency of non-motor symptoms in PD following STN DBS using the NMS Questionnaire (NMS Quest), a 30-item comprehensive questionnaire which assesses gastrointestinal, urinary, cardiovascular, sexual, cognition, mood, hallucinations/delusions and sleep dysfunction (Table 1) [45]. Though this questionnaire is not specifically geared towards only sleep, many of the symptoms evaluated occur at night and have been shown to disrupt sleep. The scale ranges from $0-30$ and a higher score represents worse nocturnal symptoms. Clinically relevant thresholds have not yet been developed for this survey.
One recent study with 116 patients demonstrated a significantly lower mean NMS Quest score in DBS patients $(6.7 \pm 3.8$ vs. $8.4 \pm 3.7, p=0.02)$ than controls at a mean follow-up of 1.9 years [46]. The DBS group also had significantly less overall percentage of sleep (44.6\% vs. $69.8 ; p=0.01)$ and urinary complaints $(62.5 \%$ vs. $83.0 \% ; p=0.02)$ compared to controls [46]. Kurcova et al. evaluated 24 patients and found a significant improvement in NMS scores four months after DBS $(37.2 \pm 22$ to $26.6 \pm 23.7$; $p<0.001)$ [37]. Although a significant difference in the sleep subsection was seen at one month (baseline $11.5 \pm 10.1$ to $4.9 \pm 6.6 ; p=0.001$ ), this was not sustained at four months after DBS $(11.5 \pm 10.1$ to $6.3 \pm 7.6 ; p=0.123$ ) [40]. The most conclusive data to date is from a multi-center study of 67 patients treated with STN DBS showing a significant improvement in overall NMS Quest scores at 24 months $(63.2 \pm 34.3$ to $50.4 \pm 31.3 ; p=0.001)$ [47]. Significant improvements in the urinary, hallucinations and sleep domains were also noted $(p<0.05)$ [47]. An analysis of stimulation location in this same group suggested that more ventral stimulation with DBS may be beneficial for sleep, possibly due to spread of current to the PPN area in the brainstem [48].

Despite the heterogeneity in surveys used to measure changes in sleep quality in patients with PD, there is now reasonable evidence to support the conclusion that DBS improves overall subjective quality of sleep, motor, and some non-motor symptoms of PD to varying degrees. Though these surveys rely on recall by either the patient or caretaker, which may introduce bias and confound the results, STN DBS appears to mediate sleep improvement through tremor and dystonia control throughout the night. The impact of STN DBS on nocturnal non-motor features of PD remains less clear and require further investigation.

\section{Impact of $D B S$ on $R B D$ in $P D$}

Rapid Eye Movement Behavior Disorder is a parasomnia that arises out of REM sleep and can present with an array of clinical symptoms ranging from vocalizations to violent motor behaviors in the setting of elevated tonic or phasic electromyographic chin or arm tone during REM sleep, known as loss of REM atonia [49]. RBD is a sleep disorder most commonly associated with alpha-synucleinopathies including PD, multiple system atrophy and Lewy body dementia. This disorder can lead to both self-injury and 
injury of bed partners. Long-term studies of "idiopathic" RBD have demonstrated that $91-96.6 \%$ of patients develop a neurodegenerative disorder 14 years after diagnosis $[50,51]$. The majority of these cases were alpha-synucleinopathies such as PD or Lewy body dementia [50, 51].

Little research is available regarding the impact of DBS on RBD, and only data on STN is currently available. One study evaluated REM sleep changes in ten patients with PD before and after DBS [38]. The amount of REM sleep and atonic REM increased on PSG in four patients with loss of REM atonia prior to DBS, suggesting that STN DBS may help to reduce RBD [35]. However, the percent of REM atonia relative to REM sleep was not evaluated in this study, limiting the applicability of this result. The most comprehensive study to date retrospectively evaluated 90 patients [54]. Forty-seven patients had RBD at baseline, with resolution of RBD in only one patient and development of RBD in 16 patients after one year of DBS [54]. The authors concluded that the incidence of RBD increased after DBS. However, the total equivalent doses of levodopa and dopamine agonists significantly decreased in the RBD group. As these medications have been suggested as possible treatments for RBD in PD, this reduction of medications may have simply unmasked RBD that was treated with dopamine $[54,55]$. Disease progression may also have played a role in the development of RBD. It is unclear if STN DBS therapy affects RBD, though further research is needed. To our knowledge, no studies have evaluated the interaction between GPi DBS and RBD.

\section{Impact of DBS on RLS in PD}

Restless Leg Syndrome (RLS) is defined as the urge to move one's extremities, often due to discomfort [56]. These sensations arise during periods of rest, often when attempting to fall asleep, and are usually relieved by movement [56]. This syndrome can significantly affect sleep latency, sleep efficiency and sleep quality, as well as cause a notable decrease in quality of life. Prevalence of RLS in PD has been estimated to range from $8 \%$ to $24 \%$, similar to that seen in the North American population (range 4\% to 29\%) [57-62]. A state of dopamine depletion in PD may be a potential etiologic factor for RLS, however, the underlying causative factors are poorly understood [57-60].

There has been conflicting evidence whether STN DBS helps to reduce RLS symptoms in patients with
PD. Studies evaluating RLS have used both the RLS diagnostic criteria and International Restless Legs Syndrome Study Group rating scale (IRLS rating scale) $[56,63]$. The IRLS rating scale assesses the severity of restless legs where $0-10$ is mild, $11-20$ is moderate, $21-30$ is severe and $31-40$ is very severe (Table 1). An early retrospective study evaluated 195 PD patients for RLS after treatment with STN DBS [64]. Only two patients reported mild RLS symptoms prior to DBS and suffered significant worsening of RLS symptoms, while nine patients reported new onset of RLS within 16 weeks of DBS implantation (mean IRLS rating scale $15.0 \pm 5.9$ ). This followed a reduction in mean levodopa equivalent daily doses (LEDD) of 79\%, suggesting that emergence of RLS may have been confounded by withdrawal of medications that are known treatments for this disorder. Those who did not have RLS after surgery only had a mean LEDD reduction of $40.4 \%$ suggesting dopamine medications were still high enough to treat RLS symptoms [64]. A clear study limitation was that patients were not screened for RLS at baseline. A more recent prospective study evaluated 31 patients with PD treated with STN DBS for occurrence of RLS following implantation [65]. No patients had RLS at baseline and six patients developed RLS symptoms up to 6 months following DBS surgery (median IRLS rating scale $16[14 ; 19])$. These patients were on a higher LEDD than those without RLS symptoms post-operatively, again suggesting either DBS unmasked RLS symptoms or the development of RLS was a side effect of dopamine medications, known as augmentation [65].

In contrast, a smaller prospective study of six patients with PD and RLS used the IRLS rating scale to evaluate severity of symptoms before and after STN DBS [66]. After STN DBS, there was a decrease in mean IRLS rating scale from $24.8 \pm 8.3$ to $4.0 \pm 5.8$. This was despite a $56 \%$ decrease in mean LEDD, suggesting that STN DBS can help reduce RLS symptoms [66]. These findings were confirmed by Chahine et al who studied 17 PD patients before and after STN DBS [37]. Six patients had RLS prior to STN DBS implantation with a mean IRLS rating scale of 23.0 at baseline. These scores significantly decreased to 14.8 at four weeks and 13.8 at six months post-implantation [37]. More recently, a prospective trial of 22 patients with PD undergoing STN DBS demonstrated that mean IRLS rating scale significantly improved from 19.6 to 11.8 two years post-implantation, despite a reduction in LEDD [67]. Twenty seven percent of patients experienced 
complete resolution, while 11 patients experienced at least 50\% improvement. No correlation was found between RLS improvement and reduction in PD medications, suggesting that STN DBS may have mediated this improvement [67]. Though the results of these studies are likely influenced by medication adjustments, the most recent evidence appears to suggest that STN DBS may help with RLS symptoms in the long-term.

One study has evaluated the impact of GPi DBS on RLS in five patients with PD (29). The IRLS rating scale improved from $9.8 \pm 14.0$ to $3.4 \pm 4.7$, but this was not statistically significant most likely due to study size. Other reports of the effect of GPi DBS on RLS are in non-PD patients. A case report of a patient with generalized dystonia found that RLS symptoms resolved after bilateral GPi DBS [68]. One other study found that GPi DBS implanted specifically for severe isolated RLS did not appear to significantly improve symptoms [69]. Further research is needed in this area.

\section{CONCLUSION}

Parkinson's disease has a negative impact on sleep via presence of motor and non-motor symptoms that disrupt normal sleep architecture. Various sleep disorders associated with PD also negatively impact quality of sleep. While STN and GPi DBS are proven therapies for treatment of motor complications from PD, the impact on sleep has only recently been explored. Both the STN and GPi have been shown to influence the interaction between wakefulness and sleep, with likely more impact on REM sleep in particular. DBS at both sites improves objective and subjective sleep measures in patients with PD, though there is considerably more data on STN DBS. Notably, nocturnal motor symptoms appear to significantly improve with DBS therapy. Non-motor symptoms, such as nocturia, do not appear to respond as well to DBS. Given the paucity of data, the impact of STN DBS on RBD is unclear and requires further investigation. Recent data have suggested that improvements in RLS may be mediated by STN DBS itself, despite mixed results in earlier studies. Literature regarding GPi DBS is also limited overall.

Despite the findings from studies of DBS in PD, it is difficult to separate the effect of medication adjustments from the impact of DBS as it relates to sleep issues. After DBS implantation, equivalent dopamine dosages are typically reduced. L-dopa and dopamine agonists appear to impact sleep by reducing wake after sleep onset and improving sleep efficiency, likely through treatment of nocturnal symptoms of PD [70, 71]. This may suggest DBS mediates improvement either as a direct influence on sleep circuitry or by improving PD symptoms as medications are lowered. Dopamine medications can also effectively treat RLS symptoms or create augmentation of them, with earlier onset and/or spread of symptoms from legs to other body parts. Because of this dual effect, the impact of medication adjustment on RLS symptoms following DBS is also difficult to assess. Given the complexities of interaction between the progression of PD, DBS and medications, further investigation is needed into the long-term impact of DBS on sleep architecture and sleep disorders in PD.

\section{ACKNOWLEDGMENTS}

This study was not funded.

\section{CONFLICT OF INTEREST}

Dr. Zuzuárregui reports no disclosures. Dr. Ostrem has received grant support from the Michael J. Fox Foundation, Boston Scientific, Medtronic, Cala Health, DOD Defense Advanced Research Projects Agency, Biogen, Acadia, Allergan and AbbVie.

\section{REFERENCES}

[1] Martinez-Martin P, Rodriguez-Blazquez C, Kurtis MM, Chaudhuri KR, NMSS Validation Group (2011) The impact of non-motor symptoms on health-related quality of life of patients with Parkinson's disease. Mov Disord 26, 399-406.

[2] Gómez-Esteban JC, Tijero B, Somme J, Ciordia R, Berganzo K, Rouco I, Bustos JL, Valle MA, Lezcano E, Zarranz JJ (2011) Impact of psychiatric symptoms and sleep disorders on the quality of life of patients with Parkinson's disease. J Neurol 258, 494-9.

[3] Rolinski M, Szewczyk-Krolikowski K, Tomlinson PR, Nithi K, Talbot K, Ben-Shlomo Y, Hu MT (2014) REM sleep behaviour disorder is associated with worse quality of life and other non-motor features in early Parkinson's disease. J Neurol Neurosurg Psychiatry 85, 560-566.

[4] Rijsman RM, Schoolderman LF, Rundervoort RS, Louter M (2014) Restless legs syndrome in Parkinson's disease. Parkinsonism Relat Disord 20, S5-S9.

[5] Mantovani S, Smith SS, Gordon R, O'Sullivan JD (2018) An overview of sleep and circadian dysfunction in Parkinson's disease. J Sleep Res 27, e12673.

[6] Horner RL, Peever JH (2017) Brain circuitry controlling sleep and wakefulness. Continuum 23, 955-972.

[7] Boeve BF, Dickson DW, Olson EJ, Shepard JW, Silber MH, Ferman TJ, Ahlskog JE, Benarroch EE (2007) Insights into REM sleep behavior disorder pathophysiology 
in brainstem-predominant Lewy body disease. Sleep Med $\mathbf{8}$, 60-64.

[8] Postuma RB, Adler CH, Dugger BN, Hentz JG, Shill HA, Driver-Dunckley E, Sabbagh MN, Jacobson SA, Belden CM, Sue LI, Serrano G, Beach TG (2015) REM sleep behavior disorder and neuropathology in Parkinson's disease. Mov Disord 30, 1413-1417.

[9] Fernández-Mendoza J, Lozano B, Seijo F, SantamartaLiébana E, Ramos-Platón MJ, Vela-Bueno A, FernándezGonzález F (2009) Evidence of subthalamic PGO-like waves during REM sleep in humans: A deep brain polysomnographic study. Sleep 32, 1117-1126.

[10] Bevan MD, Bolam JP (2009) Cholinergic, GABAergic, and glutamate-enriched inputs from the mesopontine tegmentum to the subthalamic nucleus in the rat. $J$ Neurosci $\mathbf{1 5}$, 7105-7120.

[11] Kita T, Kita H (2011) Cholinergic and non-cholinergic mesopontine tegmental neurons projecting to the subthalamic nucleus in the rat. Eur J Neurosci 33, 433-443.

[12] Merlino G, Lettieri C, Mondani M, Belgrado E, Devigili G, Mucchiut M, Rinaldo S, Craighero C, D'Auria S, Skrap M, Eleopra R (2014) Microsubthalamotomy improves sleep in patients affected by advanced Parkinson's disease. Sleep Med 15, 637-641.

[13] Holiga Š, Mueller K, Möller HE, Urgošík D, Růžička E, Schroeter ML, Jech R (2015) Resting-state functional magnetic resonance imaging of the subthalamic microlesion and stimulation effects in Parkinson's disease: Indications of a principal role of the brainstem. Neuroimage Clin 21, 264274.

[14] Qiu MH, Vetrivelan R, Fuller PM, Lu J (2010) Basal ganglia control of sleep-wake behavior and cortical activation. Eur J Neurosci 31, 499-507.

[15] Zhang J, Wang ZI, Baker KB, Vitek JL (2012) Effect of globus pallidus internus stimulation on neuronal activity in the pedunculopontine tegmental nucleus in the primate model of Parkinson's disease. Exp Neurol 233, 575-580.

[16] Qiu MH, Yao QL, Vetrivelan R, Chen MC, Lu J (2016) Nigrostriatal Dopamine Acting on Globus Pallidus Regulates Sleep. Cereb Cortex 26, 1430-1439.

[17] Antonini A, Landi A, Mariani C, DeNotaris R, Pezzoli G (2004) Deep brain stimulation and its effect on sleep in Parkinson's disease. Sleep Med 5, 211-214.

[18] Arnulf I, Bejjani BP, Garma L, Bonnet AM, Houeto JL, Damier P, Derenne JP, Agid Y (2000) Improvement of sleep architecture in PD with subthalamic nucleus stimulation. Neurology 55, 1732-1734.

[19] Iranzo A, Valldeoriola F, Santamaría J, Tolosa E, Rumià J (2002) Sleep symptoms and polysomnographic architecture in advanced Parkinson's disease after chronic bilateral subthalamic stimulation. J Neurol Neurosurg Psychiatry 72, 661-664.

[20] Monaca C, Ozsancak C, Jacquesson JM, Poirot I, Blond S, Destee A, Guieu JD, Derambure P (2004) Effects of bilateral subthalamic stimulation on sleep in Parkinson's disease. J Neurol 251, 214-218.

[21] Lyons KE, Pahwa R (2006) Effects of bilateral subthalamic nucleus stimulation on sleep, daytime sleepiness, and early morning dystonia in patients with Parkinson disease. J Neurosurg 104, 502-505.

[22] Amara AW, Standaert DG, Guthrie S, Cutter G, Watts RL, Walker HC (2012) Unilateral subthalamic nucleus deep brain stimulation improves sleep quality in Parkinson's disease. Parkinsonism Relat Disord 18, 63-68.
[23] Buysse DJ, Reynolds CF III, Monk TH, Berman SR, Kupfer DJ (1989) The pittsburgh sleep quality index: A new instrument for psychiatric practice and research. Psychiatry Res 28, 193-213.

[24] Bargiotas P, Eugster L, Oberholzer M, Debove I, Lachenmayer ML, Mathis J, Pollo C, Schüpbach WMM, Bassetti CL (2017) Sleep-wake functions and quality of life in patients with subthalamic deep brain stimulation for Parkinson's disease. PLoS One 12, e0190027.

[25] Johns MW (1991) A new method for measuring daytime sleepiness: The Epworth sleepiness scale. Sleep 14, 540-545.

[26] Baumann-Vogel H, Imbach LL, Sürücü O, Stieglitz L, Waldvogel D, Baumann CR, Werth E (2017) The impact of subthalamic deep brain stimulation on sleep-wake behavior: A prospective electrophysiological study in 50 Parkinson patients. Sleep 40, 5.

[27] Amara AW, Walker HC, Joop A, Cutter G, DeWolfe JL, Harding SM, Standaert DG (2017) Effects of subthalamic nucleus deep brain stimulation on objective sleep outcomes in Parkinson's disease. Mov Disord Clin Pract 4, 183-190.

[28] Eugster L, Bargiotas P, Bassetti CL, Michael Schuepbach WM (2016) Deep brain stimulation and sleep-wake functions in Parkinson's disease: A systematic review. Parkinsonism Relat Disord 32, 12-19.

[29] Tolleson CM, Bagai K, Walters AS, Davis TL (2016) A pilot study assessing the effects of pallidal deep brain stimulation on sleep quality and polysomnography in Parkinson's patients. Neuromodulation 19, 724-730.

[30] Bastien CH, Vallières A, Morin CM (2001) Validation of the Insomnia Severity Index as an outcome measure for insomnia research. Sleep Med 2, 297-307.

[31] Odekerken VJ, Boel JA, Schmand BA, de Haan RJ, Figee M, van den Munckhof P, Schuurman PR, de Bie RM, NSTAPS study group (2016) GPi vs STN deep brain stimulation for Parkinson disease: Three-year follow-up. Neurology 86, 755-761.

[32] Follett KA, Weaver FM, Stern M, Hur K, Harris CL, Luo P, Marks WJ Jr, Rothlind J, Sagher O, Moy C, Pahwa R, Burchiel K, Hogarth P, Lai EC, Duda JE, Holloway K, Samii A, Horn S, Bronstein JM, Stoner G, Starr PA, Simpson R, Baltuch G, De Salles A, Huang GD, Reda DJ; CSP 468 Study Group (2010) Pallidal versus subthalamic deepbrain stimulation for Parkinson's disease. N Engl J Med 362, 2077-2091.

[33] Weaver FM, Follett K, Stern M, Hur K, Harris C, Marks WJ Jr, Rothlind J, Sagher O, Reda D, Moy CS, Pahwa R, Burchiel K, Hogarth P, Lai EC, Duda JE, Holloway K, Samii A, Horn S, Bronstein J, Stoner G, Heemskerk J, Huang GD; CSP 468 Study Group (2009) Bilateral deep brain stimulation vs best medical therapy for patients with advanced Parkinson disease: A randomized controlled trial. JAMA 301, 63-73.

[34] Schuepbach WM, Rau J, Knudsen K, Volkmann J, Krack P, Timmermann L, Hälbig TD, Hesekamp H, Navarro SM, Meier N, Falk D, Mehdorn M, Paschen S, Maarouf M, Barbe MT, Fink GR, Kupsch A, Gruber D, Schneider GH, Seigneuret E, Kistner A, Chaynes P, Ory-Magne F, Brefel Courbon C, Vesper J, Schnitzler A, Wojtecki L, Houeto JL, Bataille B, Maltête D, Damier P, Raoul S, SixelDoering F, Hellwig D, Gharabaghi A, Krüger R, Pinsker MO, Amtage F, Régis JM, Witjas T, Thobois S, Mertens P, Kloss M, Hartmann A, Oertel WH, Post B, Speelman H, Agid Y, Schade-Brittinger C, Deuschl G; EARLYSTIM 
Study Group (2013) Neurostimulation for Parkinson's disease with early motor complications. $N$ Engl J Med 368, 610-622.

[35] Chaudhuri KR, Pal S, DiMarco A, Whately-Smith C, Bridgman K, Mathew R, Pezzela FR, Forbes A, Högl B, Trenkwalder C (2002) The Parkinson's disease sleep scale: A new instrument for assessing sleep and nocturnal disability in Parkinson's disease. J Neurol Neurosurg Psychiatry 73, 629-635.

[36] Trenkwalder C, Kohnen R, Högl B, Metta V, Sixel-Döring F, Frauscher B, Hülsmann J, Martinez-Martin P, Chaudhuri KR (2011) Parkinson's disease sleep scale-validation of the revised version PDSS-2. Mov Disord 26, 644-652.

[37] Chahine LM, Ahmed A, Sun Z (2011) Effects of STN DBS for Parkinson's disease on restless legs syndrome and other sleep-related measures. Parkinsonism Relat Disord 17, 208211.

[38] Nishida N, Murakami T, Kadoh K, Tohge R, Yamanegi M, Saiki H, Ueda K, Matsumoto S, Ishikawa M, Takahashi JA, Toda H (2011) Subthalamic nucleus deep brain stimulation restores normal rapid eye movement sleep in Parkinson's disease. Mov Disord 26, 2418-2422.

[39] Breen DP, Low HL, Misbahuddin A (2015) The impact of deep brain stimulation on sleep and olfactory function in Parkinson's disease. Open Neurol J 30, 70-72.

[40] Kurcova S, Bardon J, Vastik M, Vecerkova M, Frolova M, Hvizdosova L, Nevrly M, Mensikova K, Otruba P, Krahulik D, Kurca E, Sivak S, Zapletalova J, Kanovsky P (2018) Bilateral subthalamic deep brain stimulation initial impact on nonmotor and motor symptoms in Parkinson's disease: An open prospective single institution study. Medicine 97, e9750.

[41] Choi JH, Kim HJ, Lee JY, Yoo D, Im JH, Paek SH, Jeon B (2019) Long-term effects of bilateral subthalamic nucleus stimulation on sleep in patients with Parkinson's disease. PLoS One 14, e0221219.

[42] Deli G, Aschermann Z, Ács P, Bosnyák E, Janszky J, Faludi B, Makkos A, Kovács M, Komoly S, Balás I, Dóczi T, Kovács N (2015) Bilateral subthalamic stimulation can improve sleep quality in Parkinson's disease. J Parkinsons Dis 5, 361-368.

[43] Hjort N, Ostergaard K, Dupont E (2004) Improvement of sleep quality in patients with advanced Parkinson's disease treated with deep brain stimulation of the subthalamic nucleus. Mov Disord 19, 196-199.

[44] Hidding U, Gulberti A, Pflug C, Choe C, Horn A, Prilop L, Braaß H, Fründt O, Buhmann C, Weiss D, Westphal M, Engel AK, Gerloff C, Köppen JA, Hamel W, Moll CKE, Pötter-Nerger M (2019) Modulation of specific components of sleep disturbances by simultaneous subthalamic and nigral stimulation in Parkinson's disease. Parkinsonism Relat Disord 62, 141-147.

[45] Chaudhuri KR, Martinez-Martin P, Schapira AH, Stocchi F, Sethi K, Odin P, Brown RG, Koller W, Barone P, MacPhee G, Kelly L, Rabey M, MacMahon D, Thomas S, Ondo W, Rye D, Forbes A, Tluk S, Dhawan V, Bowron A, Williams AJ, Olanow CW (2006) International multicenter pilot study of the first comprehensive self-completed nonmotor symptoms questionnaire for Parkinson's disease: The NMSQuest study. Mov Disord 21, 916-923.

[46] Rukmini Mridula K, Borgohain R, Jabeen SA, Padmaja G, Bandaru VS, Ankathi P, Kanikannan MA, Ali Khan MS (2015) Comparison of frequencies of non motor symptoms in Indian Parkinson's disease patients on medical management versus deep brain stimulation: A case-control study. Iran J Neurol 14, 86-93.

[47] Dafsari HS, Silverdale M, Strack M, Rizos A, Ashkan K, Mahlstedt P, Sachse L, Steffen J, Dembek TA, VisserVandewalle V, Evans J, Antonini A, Martinez-Martin P, Ray-Chaudhuri K, Timmermann L; EUROPAR and the IPMDS Non Motor PD Study Group (2018) Nonmotor symptoms evolution during 24 months of bilateral subthalamic stimulation in Parkinson's disease. Mov Disord 33, 421-430.

[48] Dafsari HS, Petry-Schmelzer JN, Ray-Chaudhuri K, Ashkan K, Weis L, Dembek TA, Samuel M, Rizos A, Silverdale M, Barbe MT, Fink GR, Evans J, MartinezMartin P, Antonini A, Visser-Vandewalle V, Timmermann L; EUROPAR; IPMDS Non Motor PD Study Group (2018) Non-motor outcomes of subthalamic stimulation in Parkinson's disease depend on location of active contacts. Brain Stimul 11, 904-912.

[49] Arnaldi D, Antelmi E, St Louis EK, Postuma RB, Arnulf I (2017) Idiopathic REM sleep behavior disorder and neurodegenerative risk: To tell or not to tell to the patient? How to minimize the risk? Sleep Med Rev 36, 82-95.

[50] Iranzo A, Fernández-Arcos A, Tolosa E, Serradell M, Molinuevo JL, Valldeoriola F, Gelpi E, Vilaseca I, Sánchez-Valle R, LladóA, Gaig C, Santamaría J (2014) Neurodegenerative disorder risk in idiopathic REM sleep behavior disorder: Study in 174 patients. PLoS One 9, e89741.

[51] Galbiati A, Verga L, Giora E, Zucconi M, Ferini-Strambi L (2019) The risk of neurodegeneration in REM sleep behavior disorder: A systematic review and meta-analysis of longitudinal studies. Sleep Med Rev 34, 37-46.

[52] Zibetti M, Rizzi L, Colloca L, Cinquepalmi A, Angrisano S, Castelli L, Lanotte M, Lopiano L (2010) Probable REM sleep behaviour disorder and STN-DBS outcome in Parkinson's disease. Parkinsonism Relat Disord 16, 265-269.

[53] Bargiotas P, Debove I, Bargiotas I, Lachenmayer ML, Ntafouli M, Vayatis N, Schüpbach MW, Krack P, Bassetti CL (2019) Effects of bilateral stimulation of the subthalamic nucleus in Parkinson's disease with and without REM sleep behaviour disorder. J Neurol Neurosurg Psychiatry 90, 1310-1316.

[54] Kim YE, Jeon BS, Paek SH, Yun JY, Yang HJ, Kim HJ, Ehm G, Kim HJ, Lee JY, Kim JY (2015) Rapid eye movement sleep behavior disorder after bilateral subthalamic stimulation in Parkinson's disease. J Clin Neurosci 22, 315319.

[55] Aurora RN, Zak RS, Maganti RK, Auerbach SH, Casey KR, Chowdhuri S, Karippot A, Ramar K, Kristo DA, Morgenthaler TI; Standards of Practice Committee; American Academy of Sleep Medicine (2010) Best practice guide for the treatment of REM sleep behavior disorder (RBD). J Clin Sleep Med 6, 85-95.

[56] Allen RP, Picchietti DL, Garcia-Borreguero D, Ondo WG, Walters AS, Winkelman JW, Zucconi M, Ferri R, Trenkwalder C, Lee HB; International Restless Legs Syndrome Study Group (2014) Restless legs syndrome/WillisEkbom disease diagnostic criteria: Updated International Restless Legs Syndrome Study Group (IRLSSG) consensus criteria-history, rationale, description, and significance. Sleep Med 15, 860-873.

[57] Innes KE, Selfe TK, Agarwal P (2011) Prevalence of restless legs syndrome in North American and Western European populations: A systematic review. Sleep Med 12, 623-634. 
[58] Koo BB (2015) Restless leg syndrome across the globe: Epidemiology of the restless legs syndrome/Willis-Ekbom disease. Sleep Med Clin 10, 189-205.

[59] Trenkwalder C, Allen R, Högl B, Paulus W, Winkelmann J (2016) Restless legs syndrome associated with major diseases: A systematic review and new concept. Neurology 86, 1336-1343.

[60] Peralta CM, Frauscher B, Seppi K, Wolf E, Wenning GK, Högl B, Poewe W (2009) Restless legs syndrome in Parkinson's disease. Mov Disord 24, 2076-2080.

[61] Iranzo A, Comella CL, Santamaria J, Oertel W (2007) Restless legs syndrome in Parkinson's disease and other neurodegenerative diseases of the central nervous system. Mov Disord 22, S424-S430.

[62] Bhalsing K, Suresh K, Muthane UB, Pal PK (2013) Prevalence and profile of Restless Legs Syndrome in Parkinson's disease and other neurodegenerative disorders: A casecontrol study. Parkinsonism Relat Disord 19, 426-430.

[63] Walters AS, LeBrocq C, Dhar A, Hening W, Rosen R, Allen RP, Trenkwalder C; International Restless Legs Syndrome Study Group (2003) Validation of the International Restless Legs Syndrome Study Group rating scale for restless legs syndrome. Sleep Med 4, 121-132.

[64] Kedia S, Moro E, Tagliati M, Lang AE, Kumar R (2004) Emergence of restless legs syndrome during subthalamic stimulation for Parkinson disease. Neurology 63, 24102412.

[65] Marques A, Fantini ML, Morand D, Pereira B, Derost P, Ulla M, Debilly B, Lemaire JJ, Durif F (2015) Emergence of restless legs syndrome after subthalamic stimulation in Parkinson's disease: A dopaminergic overstimulation? Sleep Med 16, 583-588.

[66] Driver-Dunckley E, Evidente VG, Adler CH, Hillman R, Hernandez J, Fletcher G, Lyons MK (2006) Restless legs syndrome in Parkinson's disease patients may improve with subthalamic stimulation. Mov Disord 21, 1287-1289.

[67] Klepitskaya O, Liu Y, Sharma S, Sillau SH, Tsai J, Walters AS (2018) Deep brain stimulation improves restless legs syndrome in patients with Parkinson disease. Neurology 91 , e1013-e1021.

[68] Okun MS, Fernandez HH, Foote KD (2005) Deep brain stimulation of the GPi treats restless legs syndrome associated with dystonia. Mov Disord 20, 500-501.

[69] Ondo WG, Jankovic J, Simpson R, Jimenez-Shahed J (2012) Globus pallidus deep brain stimulation for refractory idiopathic restless legs syndrome. Sleep Med 13, 1202-1204.

[70] Ferreira T, Prabhakar S, Kharbanda PS (2014) Sleep disturbances in drug naive Parkinson's disease (PD) patients and effect of levodopa on sleep. Ann Indian Acad Neurol 17, 416-419.

[71] Pierantozzi M, Placidi F, Liguori C, Albanese M, Imbriani P, Marciani MG, Mercuri NB, Stanzione P, Stefani A (2016) Rotigotine may improve sleep architecture in Parkinson's disease: A double-blind, randomized, placebo-controlled polysomnographic study. Sleep Med 21, 140-144. 